\title{
Optimal health and function among the elderly: lessening severity of ADL disability
}

\author{
Nir Eynon • Chen Yamin • David Ben-Sira • \\ Moran Sagiv
}

Received: 3 February 2009 /Accepted: 2 March 2009 /Published online: 28 March 2009

(C) European Group for Research into Elderly and Physical Activity (EGREPA) 2009

\begin{abstract}
Despite mounting evidence implicating sedentary behavior as a significant risk factor among the elderly, there is a limited amount of information on the type and amount of activity needed to promote optimal health and function in older people. Overall muscle strength and mass decline $30-50 \%$ between the ages of 30 and 80 . The loss of muscle mass accounts for most of the observed loss of strength. The loss of muscle tissue is due to a decrease in the number of muscle fibers and to atrophy of the type II muscle fibers. The declining strength reduces the capacity to carry out basic activities of daily life and puts people at risk for falls and dependence on others. The objective of the present review is to examine the role of exercise training as a primary tool for increasing cardiopulmonary and muscular fitness in order to lessen the severity of disability in activities of daily living and to attain optimal health and functioning among the elderly.
\end{abstract}

Keywords Aerobic exercise · Aging · Resistance training · Sarcopenia

\section{Introduction}

The primary aging process, itself genetically associated, occurs both independently of life style and in the absence of disease [27, 29]. Increased life expectancy and the subsequent growth of the elderly population have had a marked effect on the proportion of persons with some form

\footnotetext{
N. Eynon $\cdot$ C. Yamin $\cdot$ D. Ben-Sira $\cdot$ M. Sagiv $(\bowtie)$

Genetics and Molecular Biology Laboratory, Life Sciences

Division, The Zinman College of Physical Education and Sport

Sciences at the Wingate Institute,

Netanya 42902, Israel

e-mail: moransag@012.net.il
}

of disability. Approximately $20 \%$ of persons aged 70 years or older report difficulty in performing essential activities of daily living (ADL), referred to as ADL disability [36].

Physical disability is common among older persons living within the community. The Framingham Disability Study $[33,56]$ reported that among community-dwelling persons older than 70 years of age, $49 \%$ of women and $27 \%$ of men have substantial mobility or work limitations. The high prevalence of ADL disability in our society imposes a considerable public health problem, and therefore, prevention of ADL disability is a major public health objective. This type of disability is the most severe form of disability limiting older persons' autonomy and leading to dependence. It marks a serious decline in functional health and increases the risk of outpatient care, hospitalization, nursing home admission, and death $[6,15,25,48]$.

Functional limitation is an intermediate state on the course from health to physical disability. Mobility limitation (e.g., difficulty in walking or climbing steps) is of particular interest because it is a common occurrence, is strongly related to major health outcomes, and may represent a stage in the disablement process that is amenable to intervention.

Aging-related changes occur mainly in the cardiopulmonary and skeletal muscles, bringing about a reduction in physical performance $[8,66]$. Such myocardial and peripheral functional changes include a decline in maximum heart rate, stroke volume, and heart contractility and an increase in peripheral vascular resistance. Consequently, maximal oxygen uptake $\left(\mathrm{VO}_{2}\right.$ max), the best single indicator of physical working capacity, is decreased. In older adults, a strong inverse association between physical activity and functional decline has been consistently observed [42, 57, 64, 68]. Accordingly, one may expect maximal cardiac output to decrease with aging irrespective of lifestyle due to 
genetic factors. If oxygen transport is indeed limited by maximal cardiac output, this may be calculated as the product of maximal heart rate and maximal stroke volume. The second possible cause for the reduction of $\mathrm{VO}_{2} \max$ with aging is the reduced capacity of working muscles to extract oxygen from the blood, as manifested by arteriovenous oxygen content difference at maximal effort [36]. The elderly are not generally anemic, and red blood cell content is usually well maintained [28]. Some studies have shown a correlation between $\mathrm{VO}_{2}$ max and muscle mass [17, 61]. Mitochondrial density has been found to be lower in their skeletal muscle of older individuals, which could further diminish capacity for endurance work. Thus, it may be that aging-related atrophy of skeletal muscle plays some role in the aging-related decline in work endurance [34] and strength [58].

The benefit of activity is partly mediated through the maintenance of strength and physical endurance [58], and trials of both strength and aerobic interventions have shown them to be beneficial in improving function in older adults $[52,54]$. However, despite the general benefit of exercise, individual responses to exercise vary [5]. The basis for this is unclear, but there appears to be a strong genetic component $[1,55]$. Physical performance in response to exercise appears to be influenced by the angiotensinconverting enzyme (ACE) insertion $(I)$ /deletion $(D)$ genotype in young adults, but whether this relationship can help explain variation in older individuals' response to exercise has not been well established [37].

\section{Aging considerations}

In response to stress, the age-related reduction in physiologic reserves causes a loss of regulatory or homeostatic balance. When combined with another consequence of agerelated changes, an increased perception of effort associated with submaximal work, a vicious cycle is created leading to decreased exercise capacity. This results in an elevated perception of effort, subsequently causing avoidance of activity, and finally contributing to an exacerbation of the age-related declines secondary to disuse. This is especially prevalent among patients unaware of these processes.

Human muscle strength declines at the rate of $12-14 \%$ per decade after the age of 50 years [39, 41]. This loss of strength with age is due to many factors, but is primarily attributed to a loss of muscle mass leading to sarcopenia [22]. Because sarcopenia is related to a loss of functional abilities [58], dependency [58], increased risk of falls, fractures [2, 40], and decreased bone mineral density [64], it has negative consequences for the health status and functional abilities of older adults. With advancing age, a further decrease in lean body mass may occur, together with the increase in adipose tissue mass typical with aging [13, 28, 69].
Mechanisms underlying age-associated change in body composition, such as an increase in body fat and a decrease in bone mass, are not fully understood. Decrease in GH secretion and serum IGF-1 levels with aging may have some impact on these processes. IGF-1 has been identified as a potent regulator of gene expression in skeletal muscle. Excitation-contraction uncoupling has been identified as a mechanism underlying sarcopenia in the skeletal muscle of aging mammals. The basic mechanism for excitationcontraction uncoupling is a larger number of ryanodine receptors uncoupled to dihydropyridine receptors [13]. In addition to the effects on muscle development, IGF-1 facilitates skeletal muscle dihydropyridine activity via tyrosine kinase-protein kinase C-dependent phosphorylation [14]. It has also been shown that IGF-1-dependent dihydropyridine modulation is impaired in aging skeletal muscles [60], which may explain, at least partially, the decline in muscle force with aging [53].

In middle and late adulthood, all people experience a series of progressive alterations in body composition [62]. The contraction in lean body mass reflects atrophic processes in liver, kidney, spleen, skin, bone, and skeletal muscles due to slower muscle protein synthesis. These structural changes have been considered an unavoidable result of aging. The results of cross-sectional studies suggest that sarcopenia is a major determinant of agingassociated decrements in strength [23, 59]. Sarcopenia involves significant alterations in the architecture of human muscle, which stem from a loss of some myofibers and the remodeling of those that remain $[51,70]$. It has been suggested that sarcopenia results from both a loss of myofibers and a decrease in type II fiber size [37].

In humans, age-related myofiber loss and myofiber atrophy generally involve type IIa and IIb fibers, with a greater impact seen in the IIb fibers [38, 49]. In young healthy adults, maximal oxygen uptake is determined by a combination of cardiac output and maximal oxygen extraction. If there is no pulmonary limitation (i.e., arterial desaturation), arterial oxygen content stays relatively constant up to maximal exertion, and venous oxygen content is reduced to the point that local oxygen pressure in the capillaries becomes insufficient for driving oxygen diffusion into the tissues. At maximal exertion, oxygen extraction can reach values of $140-180 \mathrm{mlO}_{2} 1^{-1}$ blood [4].

Another possible mechanism for the inability to increase oxygen extraction is mild arterial hypoxemia at maximum exercise. This is related to a misdistribution of cardiac output, i.e., over-perfusion of organs other than those in which perfusion and diffusion limitation are rapidly compromised [65]. Low oxygen extraction in the elderly may be due to physical inactivity or sarcopenia. As a consequence, mitochondrial partial dysfunction occurs due 
to unmatched or perhaps intrinsic mitochondrial function and regulation (abnormal mitochondrial function) and hence the inability of skeletal muscles to fully extract oxygen from the arterial blood due to considerably reduced normal oxygen conductance from the muscle capillary to the mitochondria [44]. The latter is most likely associated with a poor muscle microcirculatory network and capillarymyofiber dissociation [43]. The molecular defect in subjects with mitochondrial myopathies commonly involves the mitochondrial genome, with the detection of either single large-scale deletions or point mutations [46].

\section{Exercise benefits}

The force-producing capability of skeletal muscle facilitates locomotion and the successful performance of activities of daily living. Metabolically speaking, muscle is a significant contributor to the basal metabolic rate; it is the prime storage depot for body amino acids and is a key metabolic tissue involved in glucose disposal and lipid oxidation [20,47].

Exercise has various beneficial physiological effects such as improved muscle strength and bone mass and increased aerobic capacity, flexibility, and balance [16, 45, 63]. In line with these findings, the exercise programs resulted in increased physical performance, aerobic capacity (for the aerobic exercise program only), and muscle strength and in improved postural sway, which may explain the reduced risk for subsequent major disability. Observational studies suggested that regular physical exercise may be one of the most important factors preventing the onset of late-life disability [18, 31]. Clinical trials among older persons have shown that exercise programs improve aerobic capacity, walking speed, and muscle strength [11].

Muscle mass is arguably the most important determinant of functional capabilities and, as such, is an important consideration in a number of occupational and clinical settings. Load-bearing or resistance-type exercise is the primary method for the maintenance, increase, or recovery of muscle mass. This can be particularly important in settings where muscle atrophy is a risk, such as during bed rest or an airplane flight [32, 50].

Resistance strength training greatly increases muscle strength even in very old people. It produces muscle fiber hypertrophy and improves neural factors involved in force production. The recovered strength in turn enhances physical performance and facilitates more activity and independence towards the end of the life span [21]. Thus, it seems that resistance exercise is an effective countermeasure to sarcopenia.

Several investigators have documented the utility of resistance training in elderly persons of both sexes living both in institutions and in the community. In two studies, Fiatorone and colleagues [18, 19], observed frail, institu- tionalized patients with mean ages of 87 and 90 years. Their patients participated in a 10 -week program of lowerextremity resistance training at an intensity of $80 \%$ of single repetition maximum. They found that the strength of the quadriceps correlated with walking speed over a 6-m walking course and that muscle strength and short-course walking speeds increased by $113 \%$ and $12 \%$, respectively, after resistance training. Strength training has been shown to improve insulin-stimulated glucose uptake in both healthy elderly individuals and patients with manifest diabetes and likewise to improve muscle strength in both healthy elderly individuals and in elderly individuals with chronic disease. The increased strength is coupled with improved function and a decreased risk for falling injuries and fractures [12].

It has been shown that systematic strength training can lead to substantial increases in strength performance not only in middle-aged but also in elderly people. This could primarily be the result of the considerable neural adaptations observed, especially during the earlier weeks of training [26]. Thereafter, strength development in older people may also occur because of an increasing contribution of muscle hypertrophy. The basic requirements for training-induced hypertrophy and strength development in both older men and women are that the overall training intensity be high enough and the duration of the training period long enough [7, 67].

Training effect on cardiopulmonary function and muscle metabolism performance of the heart as a pump has been a major element in testing the idea that exercise ameliorates the aging process. Exercise training was associated with health benefits and specifically with decreased cardiovascular mortality in two large observational studies [30, 43].

It was recently suggested [3] that following training, the mechanism most likely to be involved is a change in the cardiac autonomic balance producing an increase or a relative dominance of the vegal component. It has long been known that exercise training reduces resting and submaximal heart rate. Several cardiac changes accompany the normal aging process, including prolongation of excitation-contraction and relaxation, an increase in afterload, increased vascular and myocardial stiffness, and decreased catecholamine sensitivity [44]. Alterations in left ventricular structure and function are a well-described and accepted component of the response to physical conditioning [If elderly or younger subjects are engaged in similar endurance training].

The training effect on cardiopulmonary function during submaximal exercise of a fixed absolute work rate is similar for younger and older individuals. Although many studies have shown a decrease in functional capacity and $\mathrm{VO}_{2} \max$ among the aging, they generally did not involve physically active older men [44]. 
Table 1 summarizes some of the changes in cardiovascular and hemodynamic variables associated with age and training. Endurance exercise training in the elderly decreased resting and submaximal exercise heart rate and systolic and diastolic blood pressure, while stroke volume increased. Marked changes are notable in elderly subjects during maximal effort in which stroke volume, cardiac output, contractility, and oxygen uptake increased, while total peripheral resistance and systolic and diastolic blood pressure decreased, thus lowering after-load which in turn facilitated left ventricular systolic and diastolic function. Table 1 also reveals that breathing efficiency is improved in the elderly following an endurance training program. These changes include reduction in lactic acid levels and increased maximal ventilation.

The most important adaptive response of skeletal muscle to endurance exercise is an augmentation of respiratory, capacity with increases in the ability to oxidize pyruvate, fatty acids, and ketones. As a result of increases in the levels of the enzymes of the malate-asparate shuttle, there is also an enhancement of the capability for mitochondrial oxidation of the reducing equivalents generated in the cytoplasm during glycolysis. The rise in muscle respiratory capacity results from an increase in muscle mitochondria and an alteration in mitochondrial composition, making skeletal muscle mitochondria more like heart mitochondria in their enzyme pattern [58]. When previously sedentary individuals were re-tested at the same absolute submaximal work rate after adapting to endurance exercise, their endurance was found to be markedly increased [10]. However, metabolic factors do not appear to determine the magnitude of $\mathrm{VO}_{2}$ max. The changes in muscle oxidative potential may play a major role in the capacity of elderly to perform ADL tasks.

The decline in muscle strength and mass during aging has been linked to a reduction in metabolic function.
Dynamic exercise increases aerobic metabolism of the exercising skeletal muscles in proportion to the mass of muscles and intensity of exertion involved. Skeletal muscle atrophy is often considered a hallmark of aging, and this deficit has profound implications for the regeneration of ATP in the muscles. Oxidative capacity declines in some skeletal muscles with advancing age [39]. Aging is associated with alterations in body composition such that there is an increase in percentage of body fat and a concomitant decline in lean body mass. Thus, significant loss in maximal force production takes place with aging $[24,35]$. These changes in muscle mass and strength may be due to alteration in the distribution of fiber types as a result of an interconversion between type I and type II muscle fibers or secondary to the preferential loss of a specific muscle fiber type [9].

An insertion $(I)$ /deletion $(D)$ polymorphism in intron 16 of the $A C E$ gene has been identified as a potential marker for the differential response to exercise. In the field of hypertension, the $D$ allele is associated with significantly higher serum ACE levels. In response to exercise, the $D$ allele has been associated with increased muscle strength and power, while the $I$ allele has been associated with better muscular endurance, although data are not entirely consistent. Since both muscle strength and endurance are determinants of physical function in older adults, maintenance of physical function could be related to ACE $I / D$ genotype. However, studies involving younger individuals suggest that a genotype effect is seen primarily in response to high physical activity levels [1].

\section{Conclusions}

Among older individuals who exercised, those with the ACE DD or ID genotypes were less likely to develop
Table 1 Endurance traininginduced changes in cardiovascular and hemodynamic variables in elderly subjects

\begin{tabular}{llll}
\hline Variable & Rest & Submax exercise & Maximal exercise \\
\hline Oxygen uptake & Unchanged & Unchanged & Increases \\
Systolic blood pressure & Decreases & Decreases & Decreases \\
Diastolic blood pressure & Decreases & Decreases & Decreases \\
Stroke volume & Decreases & Increases & Increases \\
Heart rate & Decreases & Decreases & Unchanged \\
Cardiac output & Unchanged & Unchanged & Increases \\
Contractility & Unchanged & Unchanged & Unchanged/Increases \\
Total peripheral resistance & Unchanged & Unchanged & Decreases \\
Arteriovenous $\mathrm{O}_{2}$ difference & Unchanged & Unchanged & Increases \\
VO ${ }_{2}$ max & Unchanged & Unchanged & Increases \\
Ventilation/oxygen uptake & Unchanged & Unchanged & Decreases \\
Lactic acid & Unchanged & Decreases & Decreases \\
\hline
\end{tabular}


mobility limitation than those with the II genotype. Regardless of genotype, individuals who exercised were less likely to develop mobility limitation than those who did not exercise. In well-functioning older men and women, a high level of physical activity is associated with the preservation of physical function. Although physical activity was associated with less mobility limitation for all ACE I/D genotypes, the improved risk benefit was significantly greater for those possessing the ID or DD genotypes compared with the II genotype. The physiological basis for these findings is uncertain. However, among the physically active participants, the II genotype was also associated with higher levels of total adiposity and intermuscular thigh fat. Exercise and an active lifestyle that includes walking protect against mobility loss in older men and women. However, activity effects on muscle parameters do not explain this association. These data indicate that the older person's skeletal muscle, cardiovascular system, and pulmonary function retain a high degree of trainability, with much of the improvement occurring peripherally, just as in younger individuals. Aerobic and resistance exercise programs appear to be effective nonpharmacological therapies for preventing major disability in older people.

\section{References}

1. An P, Borecki IB, Rankinen T et al (2003) Evidence of major genes for exercise heart rate and blood pressure at baseline and in response to 20 weeks of endurance training: the HERITAGE family study. Int J Sports Med 24:492-498. doi:10.1055/s-200337200

2. Aniansson A, Zetterberg C, Hedberg M et al (1984) Impaired muscle function with aging. A background factor in the incidence of fractures of the proximal end of the femur. Clin Orthop Relat Res 191:193-201

3. Baldi JC, McFarlane K, Oxenham HC et al (2003) Left ventricular diastolic filling and systolic function of young and older trained and untrained men. J Appl Physiol 95:2570-2575

4. Beck KC, Randolph LN, Bailey KR et al (2006) Relationship between cardiac output and oxygen consumption during upright cycle exercise in healthy humans. J Appl Physiol 101:1474-1480. doi:10.1152/japplphysiol.00224.2006

5. Bouchard C, Rankinen $\mathrm{T}$ (2001) Individual differences in response to regular physical activity. Med Sci Sports Exerc 33: S446-S451. doi:10.1097/00005768-200106001-00013 discussion S452-443

6. Charette SL, McEvoy L, Pyka G et al (1991) Muscle hypertrophy response to resistance training in older women. J Appl Physiol 70:1912-1916

7. Chrysohoou C, Pitsavos C, Panagiotakos DB et al (2003) The association between physical activity and the development of acute coronary syndromes in treated and untreated hypertensive subjects. J Clin Hypertens (Greenwich) 5:115-120. doi:10.1111/ j.1524-6175.2003.01734.X

8. Combaret L, Dardevet D, Bechet D et al (2009) Skeletal muscle proteolysis in aging. Curr Opin Clin Nutr Metab Care 12:37-41. doi:10.1097/MCO.0b013e32831b9c31
9. Correia LC, Lakatta EG, O'Connor FC et al (2002) Attenuated cardiovascular reserve during prolonged submaximal cycle exercise in healthy older subjects. J Am Coll Cardiol 40:1290-1297. doi:10.1016/S0735-1097(02) 02132-0

10. Cress ME, Buchner DM, Questad KA et al (1999) Exercise: effects on physical functional performance in independent older adults. J Gerontol A Biol Sci Med Sci 54:M242-M248

11. Dela F, Kjaer M (2006) Resistance training, insulin sensitivity and muscle function in the elderly. Essays Biochem 42:75-88. doi: $10.1042 / \mathrm{bse} 0420075$

12. Delbono O, O'Rourke KS, Ettinger WH (1995) Excitationcalcium release uncoupling in aged single human skeletal muscle fibers. J Membr Biol 148:211-222. doi:10.1007/BF00235039

13. Delbono O, Renganathan M, Messi ML (1997) Regulation of mouse skeletal muscle L-type Ca2+ channel by activation of the insulin-like growth factor-1 receptor. J Neurosci 17:6918-6928

14. Esmarck B, Andersen JL, Olsen S et al (2001) Timing of postexercise protein intake is important for muscle hypertrophy with resistance training in elderly humans. J Physiol 535:301-311. doi:10.1111/j.1469-7793.2001.00301.x

15. Ettinger WH Jr, Burns R, Messier SP et al (1997) A randomized trial comparing aerobic exercise and resistance exercise with a health education program in older adults with knee osteoarthritis. The Fitness Arthritis and Seniors Trial (FAST). JAMA 277:25-31. doi:10.1001/jama.277.1.25

16. Faulkner JA, Larkin LM, Claflin DR et al (2007) Age-related changes in the structure and function of skeletal muscles. Clin Exp Pharmacol Physiol 34:1091-1096

17. Ferrucci L, Izmirlian G, Leveille S et al (1999) Smoking, physical activity, and active life expectancy. Am J Epidemiol 149:645653

18. Fiatarone MA, Marks EC, Ryan ND et al (1990) High-intensity strength training in nonagenarians. Effects on skeletal muscle. JAMA 263:3029-3034. doi:10.1001/jama.263.22.3029

19. Fiatarone MA, O'Neill EF, Ryan ND et al (1994) Exercise training and nutritional supplementation for physical frailty in very elderly people. N Engl J Med 330:1769-1775. doi:10.1056/ NEJM199406233302501

20. Frischknecht R (1998) Effect of training on muscle strength and motor function in the elderly. Reprod Nutr Dev 38:167-174. doi:10.1051/rnd:19980203

21. Frontera WR, Hughes VA, Fielding RA et al (2000) Aging of skeletal muscle: a 12-yr longitudinal study. J Appl Physiol 88:1321-1326

22. Frontera WR, Hughes VA, Lutz KJ et al (1991) A cross-sectional study of muscle strength and mass in 45- to 78-yr-old men and women. J Appl Physiol 71:644-650

23. Frontera WR, Suh D, Krivickas LS et al (2000) Skeletal muscle fiber quality in older men and women. Am J Physiol Cell Physiol 279:C611-C618

24. Guralnik JM, LaCroix AZ, Branch LG et al (1991) Morbidity and disability in older persons in the years prior to death. Am J Public Health 81:443-447. doi:10.2105/AJPH.81.4.443

25. Hakkinen K, Kallinen M, Izquierdo M et al (1998) Changes in agonist-antagonist EMG, muscle CSA, and force during strength training in middle-aged and older people. J Appl Physiol 84:1341-1349

26. Hawkins S, Wiswell R (2003) Rate and mechanism of maximal oxygen consumption decline with aging: implications for exercise training. Sports Med 33:877-888. doi:10.2165/00007256200333120-00002

27. Hochberg MC, Lethbridge-Cejku M, Scott WW Jr et al (1994) Serum levels of insulin-like growth factor in subjects with osteoarthritis of the knee. Data from the Baltimore Longitudinal Study of Aging. Arthritis Rheum 37:1177-1180. doi:10.1002/ art. 1780370811 
28. Hoeldtke RD, Cilmi KM (1985) Effects of aging on catecholamine metabolism. J Clin Endocrinol Metab 60:479-484

29. Hu G, Tuomilehto J, Silventoinen K et al (2004) Joint effects of physical activity, body mass index, waist circumference and waistto-hip ratio with the risk of cardiovascular disease among middleaged Finnish men and women. Eur Heart J 25:2212-2219. doi:10.1016/j.ehj.2004.10.020

30. Hubert HB, Bloch DA, Fries JF (1993) Risk factors for physical disability in an aging cohort: the NHANES I Epidemiologic Followup Study. J Rheumatol 20:480-488

31. Hyatt RH, Whitelaw MN, Bhat A et al (1990) Association of muscle strength with functional status of elderly people. Age Ageing 19:330-336. doi:10.1093/ageing/19.5.330

32. Jette AM, Branch LG (1981) The Framingham Disability Study: II. Physical disability among the aging. Am J Public Health 71:1211-1216. doi:10.2105/AJPH.71.11.1211

33. Kallinen M, Suominen H, Vuolteenaho O et al (1998) Effort tolerance in elderly women with different physical activity backgrounds. Med Sci Sports Exerc 30:170-176. doi:10.1097/ 00005768-199801000-00024

34. Klein CS, Marsh GD, Petrella RJ et al (2003) Muscle fiber number in the biceps brachii muscle of young and old men. Muscle Nerve 28:62-68. doi:10.1002/mus.10386

35. Kramarow E, Lentzner H, Rooks R et al (1999) Health and Aging Chartbook: Health, United States. National Center for Health Statistics, Hyattsville

36. Kritchevsky SB, Nicklas BJ, Visser M et al (2005) Angiotensinconverting enzyme insertion/deletion genotype, exercise, and physical decline. JAMA 294:691-698. doi:10.1001/jama.294.6.691

37. Lexell J, Downham D (1992) What is the effect of ageing on type 2 muscle fibres? J Neurol Sci 107:250-251. doi:10.1016/0022510X(92) 90297-X

38. Lindle RS, Metter EJ, Lynch NA et al (1997) Age and gender comparisons of muscle strength in 654 women and men aged 2093 yr. J Appl Physiol 83:1581-1587

39. Lord SR, Ward JA, Williams P et al (1994) Physiological factors associated with falls in older community-dwelling women. J Am Geriatr Soc 42:1110-1117

40. Lynch NA, Metter EJ, Lindle RS et al (1999) Muscle quality. I. Age-associated differences between arm and leg muscle groups. J Appl Physiol 86:188-194

41. Malmberg J, Miilunpalo S, Pasanen M et al (2005) Characteristics of leisure time physical activity associated with risk of decline in perceived health - a 10-year follow-up of middle-aged and elderly men and women. Prev Med 41:141-150. doi:10.1016/j. ypmed.2004.09.036

42. Marrades RM, Roca J, Campistol JM et al (1996) Effects of erythropoietin on muscle $\mathrm{O} 2$ transport during exercise in patients with chronic renal failure. J Clin Invest 97:2092-2100. doi:10.1172/JCI118646

43. McGuire DK, Levine BD, Williamson JW et al (2001) A 30-year follow-up of the Dallas Bedrest and Training Study: II. Effect of age on cardiovascular adaptation to exercise training. Circulation 104:1358-1366. doi:10.1161/hc3701.096099

44. Messier SP, Royer TD, Craven TE et al (2000) Long-term exercise and its effect on balance in older, osteoarthritic adults: results from the Fitness, Arthritis, and Seniors Trial (FAST). J Am Geriatr Soc 48:131-138

45. Metivier F, Marchais SJ, Guerin AP et al (2000) Pathophysiology of anaemia: focus on the heart and blood vessels. Nephrol Dial Transplant 15(Suppl 3):14-18. doi:10.1093/ndt/15.suppl_6.14

46. Moore DR, Burd NA (2009) Exercise intensity matters for both young and old muscles. J Physiol 587:511-512. doi:10.1113/ jphysiol.2008.166744

47. Mor V, Wilcox V, Rakowski W et al (1994) Functional transitions among the elderly: patterns, predictors, and related hospital use.
Am J Public Health 84:1274-1280. doi:10.2105/AJPH.84.8. 1274

48. Moulias R, Meaume S, Raynaud-Simon A (1999) Sarcopenia, hypermetabolism, and aging. Z Gerontol Geriatr 32:425-432. doi:10.1007/s003910050140

49. Nagi S (1991) Disability in America: Toward a national Agenda for Prevention. In: Disability concepts revisited: implications for prevention in America. National Academy Press, Washington DC, pp 309-327

50. Narici MV, Maganaris CN, Reeves ND et al (2003) Effect of aging on human muscle architecture. J Appl Physiol 95:22292234

51. Newman AB, Haggerty CL, Kritchevsky SB et al (2003) Walking performance and cardiovascular response: associations with age and morbidity - the Health, Aging and Body Composition Study. J Gerontol A Biol Sci Med Sci 58:715-720

52. Nilsson A, Isgaard J, Lindahl A et al (1986) Regulation by growth hormone of number of chondrocytes containing IGF-I in rat growth plate. Science 233:571-574. doi:10.1126/science. 3523759

53. Penninx BW, Messier SP, Rejeski WJ et al (2001) Physical exercise and the prevention of disability in activities of daily living in older persons with osteoarthritis. Arch Intern Med 161:2309-2316. doi:10.1001/archinte.161.19.2309

54. Perusse L, Rankinen T, Rauramaa R et al (2003) The human gene map for performance and health-related fitness phenotypes: the 2002 update. Med Sci Sports Exerc 35:1248-1264. doi:10.1249/ 01.MSS.0000078938.84161.22

55. Pinsky JL, Jette AM, Branch LG et al (1990) The Framingham Disability Study: relationship of various coronary heart disease manifestations to disability in older persons living in the community. Am J Public Health 80:1363-1367. doi:10.2105/ AJPH.80.11.1363

56. Rantanen T (2003) Muscle strength, disability and mortality. Scand J Med Sci Sports 13:3-8. doi:10.1034/j.1600-0838.2003. 00298.x

57. Rantanen T, Era P, Heikkinen E (1997) Physical activity and the changes in maximal isometric strength in men and women from the age of 75 to 80 years. J Am Geriatr Soc 45:14391445

58. Rantanen T, Guralnik JM, Sakari-Rantala R et al (1999) Disability, physical activity, and muscle strength in older women: the Women's Health and Aging Study. Arch Phys Med Rehabil 80:130-135. doi:10.1016/S0003-9993(99) 90109-0

59. Renganathan M, Sonntag WE, Delbono O (1997) L-type Ca2+ channel-insulin-like growth factor-1 receptor signaling impairment in aging rat skeletal muscle. Biochem Biophys Res Commun 235:784-789. doi:10.1006/bbrc.1997.6881

60. Ryall JG, Schertzer JD, Lynch GS (2008) Cellular and molecular mechanisms underlying age-related skeletal muscle wasting and weakness. Biogerontology 9:213-228. doi:10.1007/s10522-0089131-0

61. Sinaki M (2007) The role of physical activity in bone health: a new hypothesis to reduce risk of vertebral fracture. Phys Med Rehabil Clin N Am 18:593-608. doi:10.1016/j.pmr.2007.04.002 xi-xii

62. Sinaki M, McPhee MC, Hodgson SF et al (1986) Relationship between bone mineral density of spine and strength of back extensors in healthy postmenopausal women. Mayo Clin Proc 61:116-122

63. Singh MA (2002) Exercise comes of age: rationale and recommendations for a geriatric exercise prescription. J Gerontol A Biol Sci Med Sci 57:M262-M282

64. Taylor R, Turnbull D (1997) Laboratory diagnosis of mitochondrial disease. Laboratory diagnosis of mitochondrial disease. In: Applegarth D, Dimmick J, Hall J (eds) Organelle diseases clinical 
feature, diagnosis, pathogenesis and management. Chapman \& Hall, New York, pp 341-350

65. Thomas L, Levett K, Boyd A et al (2003) Changes in regional left atrial function with aging: evaluation by Doppler tissue imaging. Eur J Echocardiogr 4:92-100. doi:10.1053/euje.2002. 0622

66. Treuth MS, Ryan AS, Pratley RE et al (1994) Effects of strength training on total and regional body composition in older men. $\mathrm{J}$ Appl Physiol 77:614-620

67. Visser M, Simonsick EM, Colbert LH et al (2005) Type and intensity of activity and risk of mobility limitation: the mediating role of muscle parameters. J Am Geriatr Soc 53:762-770. doi:10.1111/j.1532-5415.2005.53257.x

68. Weiss EP, Spina RJ, Holloszy JO et al (2006) Gender differences in the decline in aerobic capacity and its physiological determinants during the later decades of life. J Appl Physiol 101:938944. doi:10.1152/japplphysiol.01398.2005

69. Welle S (1998) Growth hormone and insulin-like growth factor-I as anabolic agents. Curr Opin Clin Nutr Metab Care 1:257-262. doi:10.1097/00075197-199805000-00004

70. Welle S (2002) Cellular and molecular basis of age-related sarcopenia. Can J Appl Physiol 27:19-41 